\title{
SCLEROTHERAPY - FROM HISTORICAL RESEARCH TO THE MODERN AND EFFICIENT METHOD OF PHLEBOLOGICAL TREATMENT
}

\author{
Joanna Borecka-Sobczak \\ Phlebological Clinic, Gdańsk, Poland
}

\section{ABSTRACT}

Venous insufficiency most likely accompanied humanity from the moment that man adopted an upright posture. The beginnings of sclerotherapy go back many years - it was in the Classical Era that Hippocrates recommended puncturing varicose veins. In fact, minimally invasive treatment became available only in the mid-nineteenth century, when Francis Rynd invented the hypodermic needle, and Charles-Gabriel Pravaz in 1851 introduced a hypodermic syringe. It was already more than 100 years ago that chemicals were injected into veins to get rid of varicose veins. The pioneer of phlebology is considered to be Professor Paul Linser. In the 1920s, he used 1-2\% mercury perchloride injection in over 6000 patients. In the 1960s, George Fegan presented modern compression sclerotherapy in the journal The Lancet, which again popularized this method. In 1963 Doctor Peter Lunkenheimer used polidocanol for the first time in his patient. The era of foam sclerotherapy began when, in 1939, Stuart McAusland performed and described obliteration with foam. The introduction of ultrasound to sclerotherapy was a milestone along with the discovery that foam is visible on ultrasound. The precision of the method has reached an unprecedented level. Contemporary guidelines for sclerotherapy were presented in a document during a Guideline Conference held by the German Society of Phlebology in 2012. In the $21^{\text {st }}$ century, along with the development of minimally invasive medicine, sclerotherapy has once again gained an important position in the treatment of veins.
\end{abstract}

Key words: sclerotherapy, varicose veins, history of vein treatment, venous insufficiency.

\author{
REVIEW PAPER \\ Phlebological Review 2021; 29, 1: 1-6 \\ Submitted: 10.05 .2021 \\ Accepted: 19.05.2021 \\ ADDRESS FOR CORRESPONDENCE \\ Joanna Borecka-Sobczak \\ Phlebological Clinic \\ 27 Partyzantów St. \\ 80-254 Gdańsk, Poland \\ e-mail: jbs.poradnia@gmail.com
}

DOI: https://doi.org/10.5114/pr.2021.106557

\section{INTRODUCTION}

Venous insufficiency of the lower extremities most likely accompanied humanity from the moment man adopted an upright posture. From then on, the veins had to do a lot more work to bring the blood to the heart [1]. The first illustration of a varicose vein, discovered at the foot of Acropolis in Athens and dating back to the 4th century BC, was dedicated to Dr Amynos, perhaps one of the first phlebologists [2]. The beginnings of sclerotherapy go back many years - it was in the Classical Era that Hippocrates recommended puncturing varicose veins and described incidental obliteration, which occurred after the inflammation resulting from such a puncture of the varicose veins $[1,3]$. And it all happened even before William Harvey (1578-1657) discovered blood circulation.

\section{THE BEGINNINGS OF SCLEROTHERAPY}

For years, there has been a search for the treatment of varicose veins, in which the major focus has been on surgical treatment, although not all doctors have recommended such an approach. In the $17^{\text {th }}$ century such methods were not very popular [2], and bandages were recommended for the treatment of varicose veins and ulcers. It was in that period that a royal physician, Richard Wiseman, invented a stocking made of delicate skin (preferably dog skin) and proposed it for the treatment of venous shin ulcers [4-6].

Until the end of the $19^{\text {th }}$ century, surgical treatment was very traumatic because there were no antiseptics and no anaesthesia; Richard Wiseman claimed that such treatment was painful, caused large "bumps", wounds, and bleeding [4].

Simultaneously with surgical methods, alternative forms of therapy were sought. It was noticed that in the wake of inflammation of varicose veins their reduction and/or obliteration could be observed. Initially, an agent was injected perivascularly, which caused irritation of the surrounding tissues, and inflammation of the vessel and its obliteration. 
The first attempts to apply this method were made in the $17^{\text {th }}$ century by Eisholz, and in Switzerland by Zollikofer. At that time, alcohol and acid were injected into the veins, and it is not known whether the patients survived $[1,7]$.

Minimally invasive treatment became available only in the mid-nineteenth century, when the Irish physician Francis Rynd invented the hypodermic needle (in 1845), and the French Charles-Gabriel Pravaz in 1851 designed and introduced a hypodermic syringe, with which he originally treated aneurysms $[3,7]$.

Thanks to the new syringe, the injection therapy could develop more dynamically. In 1853 in Vienna, Charles-Gabriel Pravaz and Eduard Chassaignac applied iron perchloride for the purpose of vein obliteration in 32 patients [2,3]. Also, in Lyon, professor of surgery Joseph Pierre Pétrequin together with professor of pharmacy Prof. Soquet concluded that an iodine-tannin solution could give better results than iron perchloride, and at the Congress in Paris in 1853 they presented the preliminary results of injections with this agent made in 16 patients. Next, in 1875, they presented the results of treating 200 patients with such a solution with good results and without severe complications [7].

Hence, it was already more than 100 years ago that chemicals were injected into veins to cure varicose veins. Various substances were then used to heal varicose veins, such as: 5\% phenol, perchlorate and iron perchloride, $20 \% \mathrm{NaCl}, 60 \%$ glucose, sodium morrhuate, iodine solutions, alcohol solutions, sodium salicylate, and chromic alum of glycerol. Unfortunately, it was not yet understood what caused the sepsis or what the effects of the use of a caustic solution were. Most of the agents used were toxic, so there were complications in the form of infections, inflammations, severe pain and swelling, as well as focal skin necrosis, which discouraged further attempts. The resultant inflammatory reaction was so strong that sclerotherapy continued to be overshadowed by surgical treatment. In 1894, the Surgical Congress in Lyon went as far as to condemn the method due to its complications and the lack of satisfactory results $[3,7]$.

\section{THE DEVELOPMENT OF SCLEROTHERAPHY IN THE $20^{\text {TH }}$ CENTURY}

The pioneer of phlebology is considered to be Professor Paul Linser (1871-1963), a German physician, the first head of the Department of Dermatology and Venereology at the University of Tübingen. In the early 1900s, he noticed that the mercurial preparation used to treat syphilis caused sclerosis of the veins in his arm, so he began to apply it in varicose vein treatment.

In the 1920s, Paul Linser started to use a $1-2 \%$ mercury perchloride injection, which he gave to over 6000 patients. Later, his assistant, Karl Linser (1895-1976), who also became a professor, used $22 \%$ sodium chloride when iron was found to be nephrotoxic $[1,3,7]$. Therefore, the search for a substance that would be effective and at the same time had fewer side effects continued.

More or less at the same time, a flexible internal saphenous stripper was developed by Babcock and vein surgery was becoming increasingly precise, and in 1911 Ehrlich proved the safety of chemically induced thrombosis. It was then that sclerotherapy became more popular; however, the fear of fatal pulmonary embolism discouraged some medics from applying this method of treatment. Nevertheless, in subsequent decades, numerous doctors used sclerotherapy, improving the method [2].

Professor Sicard, a neurologist, and his colleagues found that luargol, which was used to treat syphilis, caused thrombosis, and that this was due to the presence of sodium bicarbonate in the solution. They used the solution to treat varicose veins in several thousand patients [7].

In the 1940s sclerotherapy was not popular. However, a publication by Egmont James Orbach in 1944 introduced the air-block technique, which involved injecting first a small amount of air into a vein $\left(1 \mathrm{~cm}^{3}\right)$ and then the medicine in the form of a solution. Currently, this technique is not used, but some phlebologists use its modification, i.e. the foam-block techniques, invented by the Swiss doctor Karl Sigg in 1949, where instead of air an large-bubble foam is introduced into the vein $[8,9]$.

In his publication Orbach listed the types of sclerosing agents used in sclerotherapy and mentioned a new synthetic surface active substance - sodium tetradecyl sulphate (STS) [9].

A breakthrough in the treatment with this method was the development of STS in 1946 and its use by the German surgeon Leopold Reiner. This medicine proved much more effective and at the same time caused fewer complications [7].

In the 1960s, the Irishman George Fegan presented modern compression sclerotherapy in The Lancet (1963), which again popularized this method. In the article, entitled "Continuous compression technique of injecting varicose veins", he described a study involving over 13,000 patients. He treated varicose veins with $3 \%$ STS injections, administering $0.5 \mathrm{~mL}$ into one area, giving 10-20 shots in a single session. During treatment, finger pressure was applied on each side of the place of injection, and immediately afterwards a bandage was wound there. Next, an elastic stocking was put on, which the patient would wear continuously day and night until the next visit. Pregnancy or a history of deep vein thrombosis were not contraindications [10].

At around the same time, German pharmaceutical company BASF, which produced polidocanol, abandoned its use as an anasthetic because it was found to induce venous thrombosis. And so, by chance, it turned out that the substance could be a good sclerosant. Otto Henschel, the then scientific director of Kreussler Pharma in Germany, became interested in this substance, and in 1963. 
Dr Peter Lunkenheimer used polidocanol for the first time in his patient $[3,7]$.

In the 1960s, sclerotherapy became more popular than surgery, but in the 1970s, surgery took the lead again due to better outcomes in long-term studies.

In the article entitled "Quick treatment - a modified method of sclerotherapy of varicose veins" published in the Vasa journal in 1975, Sigg and Zelikovski described 58,000 cases of sclerotherapy treatment $[2,11]$.

In the following years, two methods of sclerotherapy were applied: the Tournay method and the Sigg method. The first one involves injection and introduction of a sclerosant being made to a patient in a horizontal position. The Sigg method, which is more complicated, recommends puncturing the vein in an upright position, then the patient lies down, which causes the vein to empty, and the sclerosant is injected, possibly with preceding injection of air into the vein (air-block) [1].

\section{FOAM SCLEROTHERAPY}

Initially, sclerotherapy treatment involved the use substances in the form of a liquid; however, it was later noticed that by foaming some solutions better treatment results could be obtained with smaller amounts of medicine.

The era of foam sclerotherapy began when, in 1939 , Stuart McAusland performed and described obliteration with foam (obtained by shaking sodium morrhuate) injected into telangiectasia. He popularized this technique in the United States. The technique has since been improved in various ways (double-syringe system, lowand high-pressure techniques) $[2,3,7,12]$.

The agents that can be foamed are those that damage endothelial cells by reacting with lipids (STS and polidocanol). The method has been in use to this day. Alcohol, which was one of the first sclerosants, is still used to close and to eliminate vascular malformations.

Unfortunately, the continuing problem was the lack of foam standardization (gas proportions, sclerosant concentration, bubble size) [2].

In 1995, Cabrera Garido was the first to use a modification of the method, which involved addition of $\mathrm{CO}_{2}$, being a safer gas. However, the resultant foam had bubbles that disintegrated quickly. In 2000, Tessari introduced a method with two syringes connected by a three-way stopcock, in which one syringe contains the medicine, the other contains air in proportions of 1 to 4 , and the pistons that move alternately generate microfoam $[7,8]$.

\section{ULTRASOUND-GUIDED SCLEROTHERAPY}

The next milestone in the treatment of varicose veins was the use of Doppler ultrasound for the purposes of vascular diagnostics. Initially, the use of "blind" Doppler (Continuous Wave Doppler) enabled localization of the vessel. Next, with the development of imaging diagnostics - colour and pulsed Doppler, thanks to which an accurate image of the vessel could be obtained - it became possible to inject the sclerosing agents precisely into the centre of the vessel. The first ultrasound-guided sclerotherapy procedure was performed by Schadeck in Paris in 1984 [7].

Echosclerotherapy is a sclerotherapy of the main superficial venous trunks - great saphenous vein and small saphenous vein - where the obliterating agent is injected under direct ultrasound guidance. Ultrasound makes it possible to observe how the injected foam travels. The course of even small veins can be traced using ultrasound, as a result of which the procedure is more precise $[8,13]$.

Many details began to be considered, for example whether the type of material the syringe used for treatment is made of affects the stability of foam, and what type of needle does not destabilize the foam. The method has been getting more and more precise $[13,14]$.

Currently, high frequency linear probes are available. Before and after the procedures, ultrasound checks are performed. Today, practically every sclerotherapy is performed under ultrasound guidance [15].

\section{SCLEROTHERAPY MODIFICATIONS IN THE $21^{\text {ST }}$ CENTURY}

In the 21st century, along with the development of minimally invasive medicine, sclerotherapy has once again gained an important position in the treatment of veins.

In Poland, sclerotherapy began to be used more widely around 2000. It is still developing, and an increasing number of phlebology centres are being established.

The sclerotherapy agents that are used nowadays come in the form of a liquid or a foam that is usually created following the Tessari method with the use of air. It is not uncommon to combine liquid and foam, whose concentrations depend on the vein diameter [13].

Contemporary guidelines for sclerotherapy were presented in a document drafted on behalf of 23 different European Phlebology Societies during a Guideline Conference held by the German Society of Phlebology in Mainz between 7 and 10 May 2012.

Sclerotherapy is recommended for all types of veins, in particular:

- incompetent saphenous veins (grade 1A),

- incompetent tributaries of saphenous veins (grade 1B),

- incompetent perforating veins (grade 1B),

- reticular varicose veins (grade 1A),

- telangiectasias (grade 1A),

- residual and recurrent varicose veins after previous interventions (grade 1B),

- varicose veins of pelvic origin (grade 1B),

- varicose veins (refluxing veins) in proximity of leg ulcers (grade 1B),

- venous malformations (grade 1B) [16]. 
Over the past 10 years, since in-office ultrasound has become a standard, there have been many modifications to this method, such as sclerotherapy with a catheter, with the use of cannulas, the ScleroSafe system, as well as mechanical-chemical methods such as the Flebogrif and ClariVein systems [17-19].

Moreover, sclerotherapy often applies tumescent anaesthesia so as to shrink the vein as much as possible, which increases the likelihood of its closure with the use of less of the medicine.

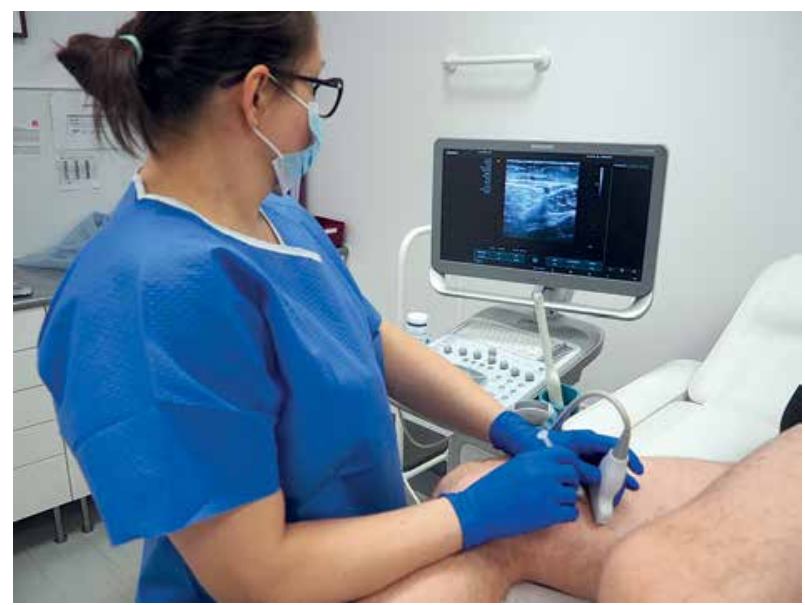

Fig. 1. Echosclerotherapy of the great saphenous vein - ultrasound-guided vein puncture

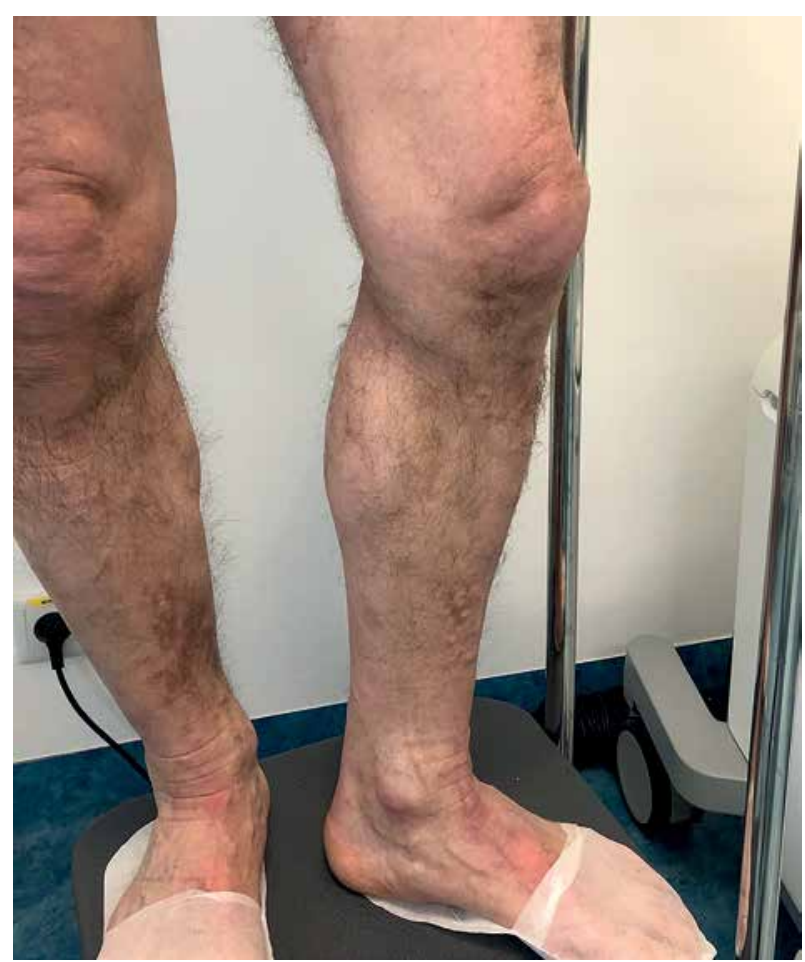

Fig. 3. Incompetent great saphenous vein and inflows-varicose veins - after sclerotherapy
One of the methods often used in hybrid or combined treatment is obliteration. For example, laser thermal ablation of the great saphenous vein or the small saphenous vein and sclerotherapy of varicose veins are performed simultaneously [19].

Some phlebologists use various assisting devices, such as vein illuminators, which also adds to the accuracy of the procedure.

Examples of the current use of sclerotherapy are presented in the figures below.

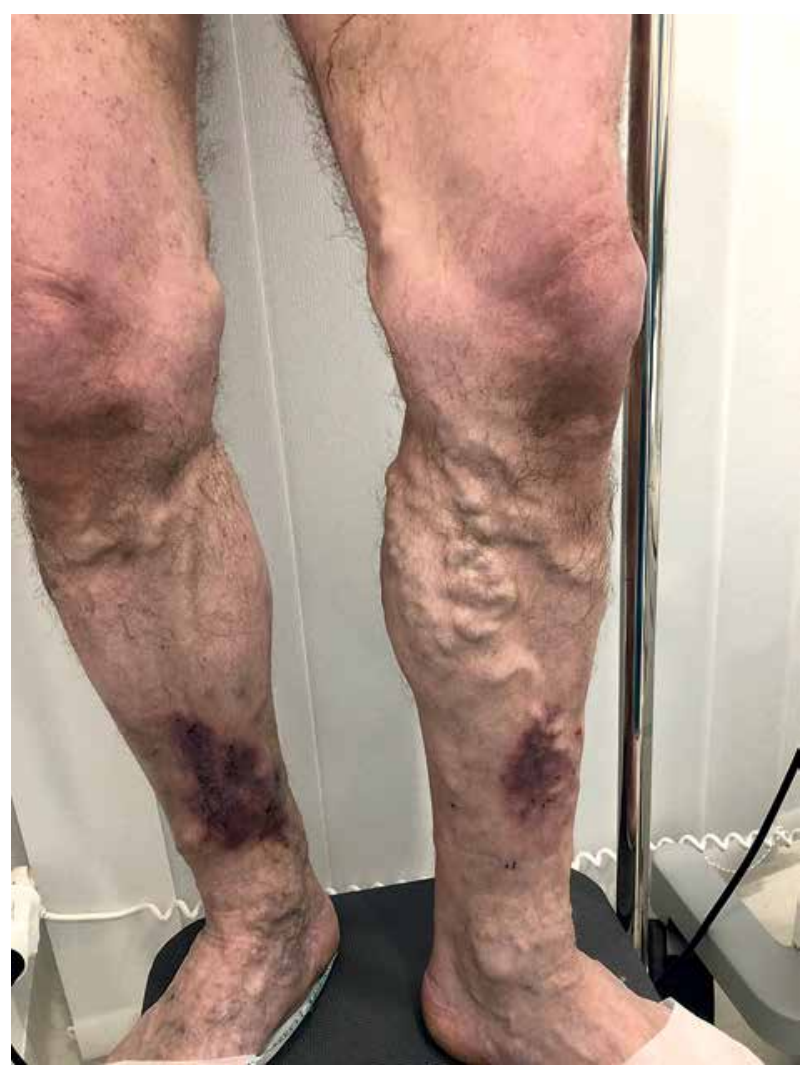

Fig. 2. Incompetent great saphenous vein and inflows-varicose veins - before sclerotherapy

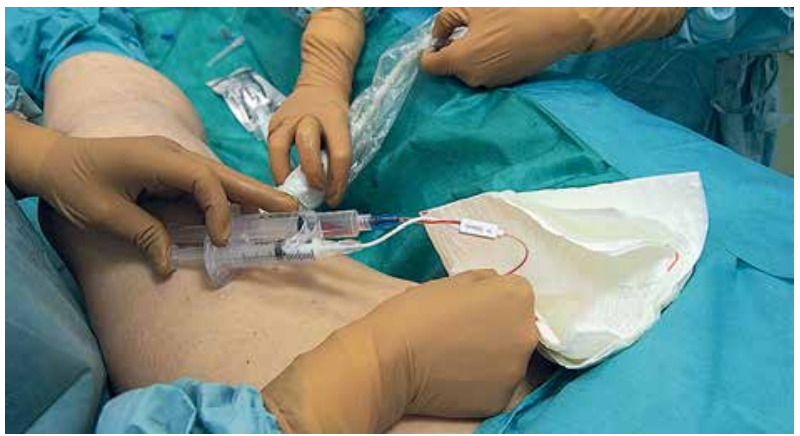

Fig. 4. Intravenous treatment - ScleroSafe system 


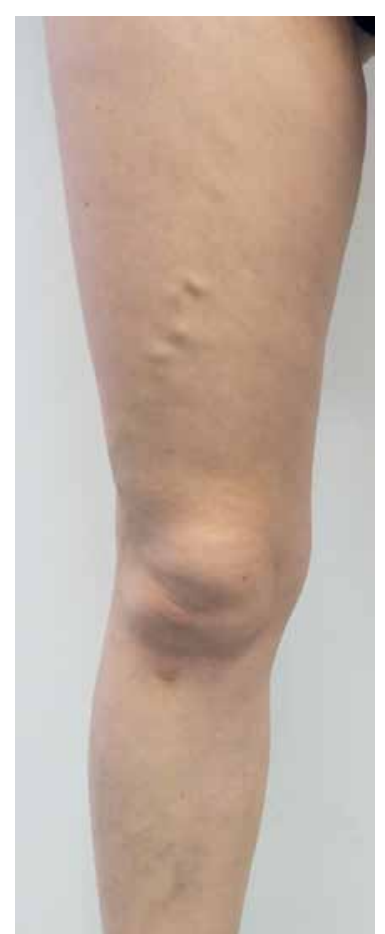

Fig. 5. Incompetent anterior accessory saphenous vein before sclerotherapy

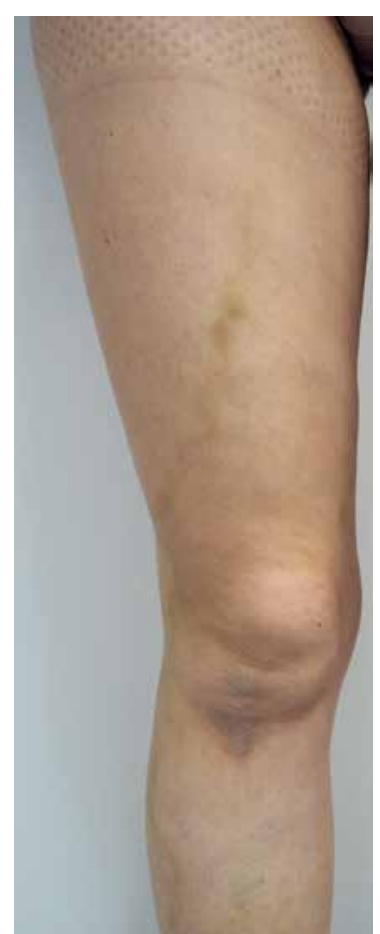

Fig. 6. Incompetent anterior accessory saphenous vein three weeks after sclerotherapy

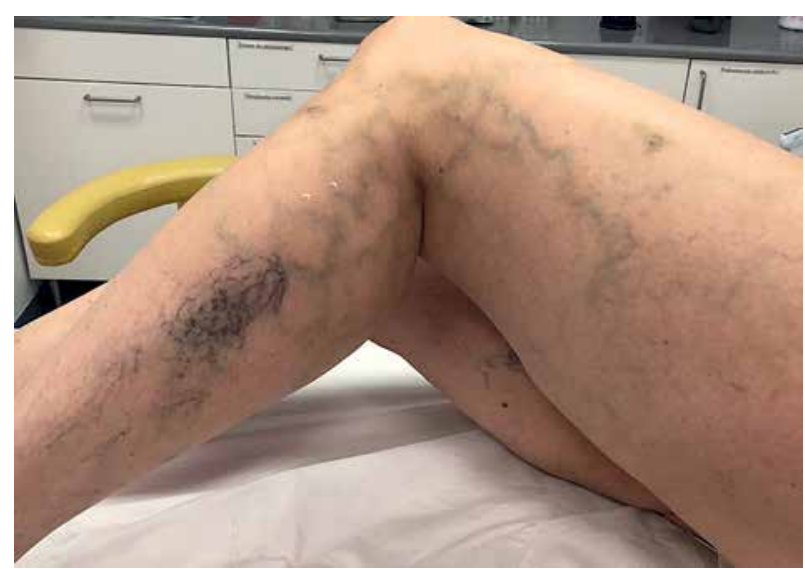

Fig. 7. Reticular varicose veins and telangiectasias before sclerotherapy

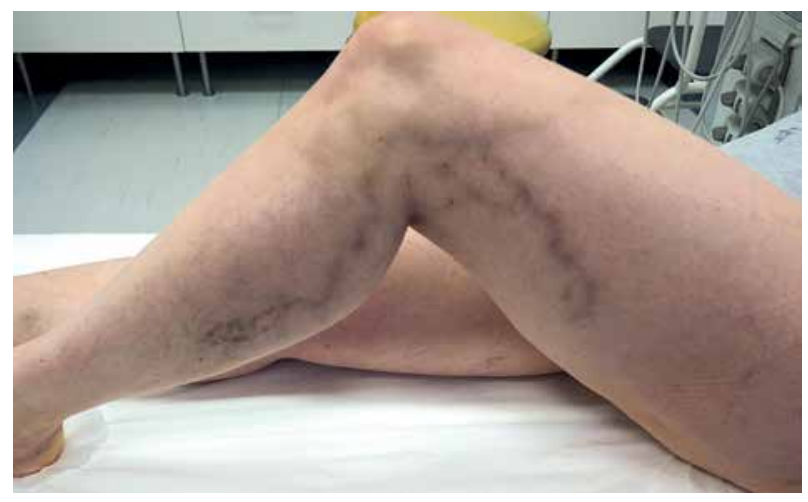

Fig. 8. Reticular varicose veins and telangiectasias three weeks after sclerotherapy

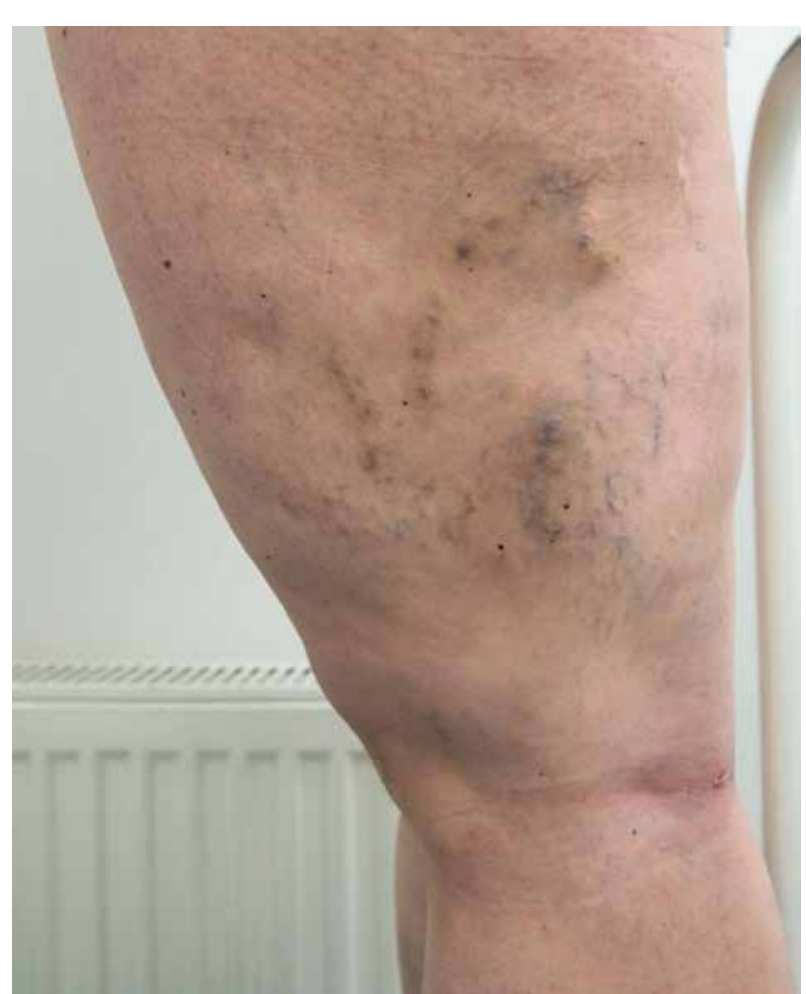

Fig. 10. Telangiectasias three weeks after sclerotherapy
Fig. 9. Telangiectasias before sclerotherapy

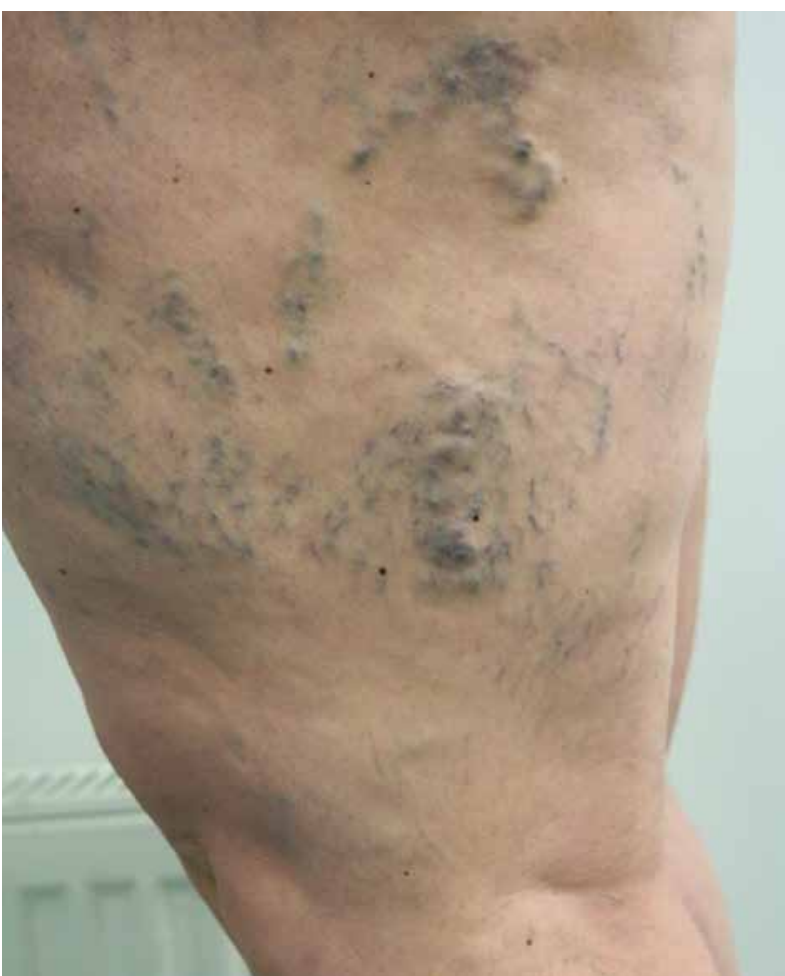




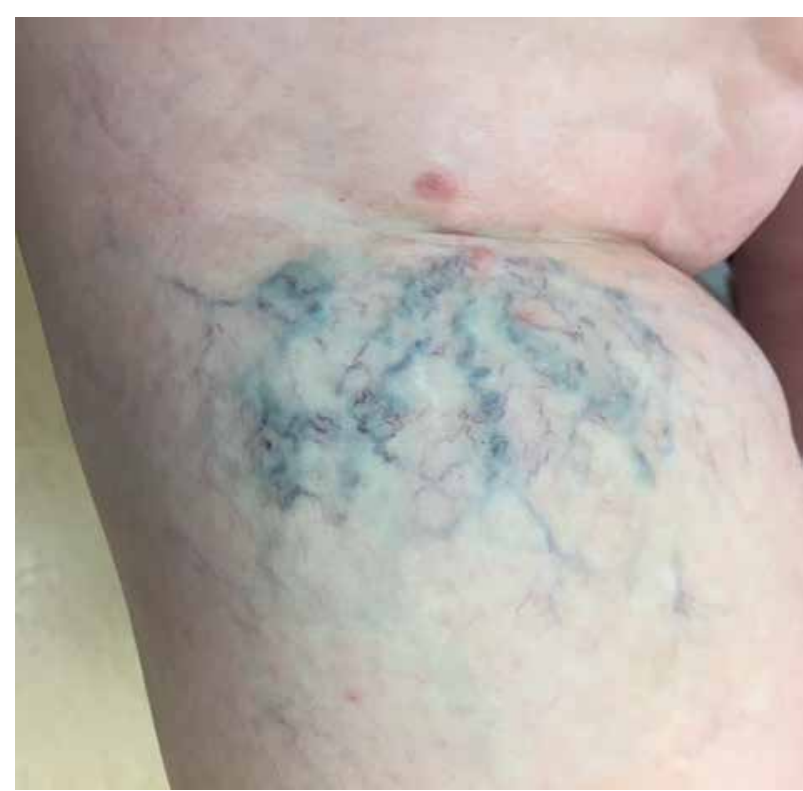

Fig. 11. Incompetent popliteal perforating vein before sclerotherapy

\section{CONCLUSIONS}

Medicine has always aimed to help with suffering. Since ancient times, when surgery was not a safe method, injections into varicose veins were already performed. Unfortunately, the injected substances were often toxic and caused numerous painful complications.

The first revolution came with a syringe for injection devised by Pravaz. The next step leading us to today's sclerotherapy was the discovery of foam by McAusland. Finally, effective and safe substances were developed STS and polidocanol - which are used to this day.

A milestone was the introduction of ultrasound to sclerotherapy and the discovery that foam is visible on ultrasound. The precision of the method has reached an unprecedented level. And although there is still nothing to replace the experience of a doctor, never before has such minimally invasive treatment been possible as is nowadays.

\section{The author declares no conflict of interest.}

\section{REFERENCES}

1. Milik K, Gembal P, Kęsik J, Zubilewicz T. Leczenie operacyjne chorób żylnych i urazów żył kończyn dolnych na przestrzeni dziejów. Chir Pol 2006; 8: 269-273.

2. Van den Bremer J, Moll FL. Historical overview of varicose vein surgery. Ann Vasc Surg 2010; 24: 426-432.

3. Kózka M, Snarska A, Drygalski T, Dolecki M. Zabiegowe leczenie żylaków na przestrzeni wieków. Przegl Lek 2007; 64: 7-8.

4. Royle J, Somjen GM. Varicose veins: Hippocrates to Jerry Moore. ANZ J Surg 2007; 77: 1120-1127.

5. Janbon C, Laborde JC, Quere I. History of the treatment of varices. J Mal Vasc 1994; 19: 210-215.

6. Sumner DS. Presidential address: entering the third millennium. J Vasc Surg 2000; 32: 833-839.

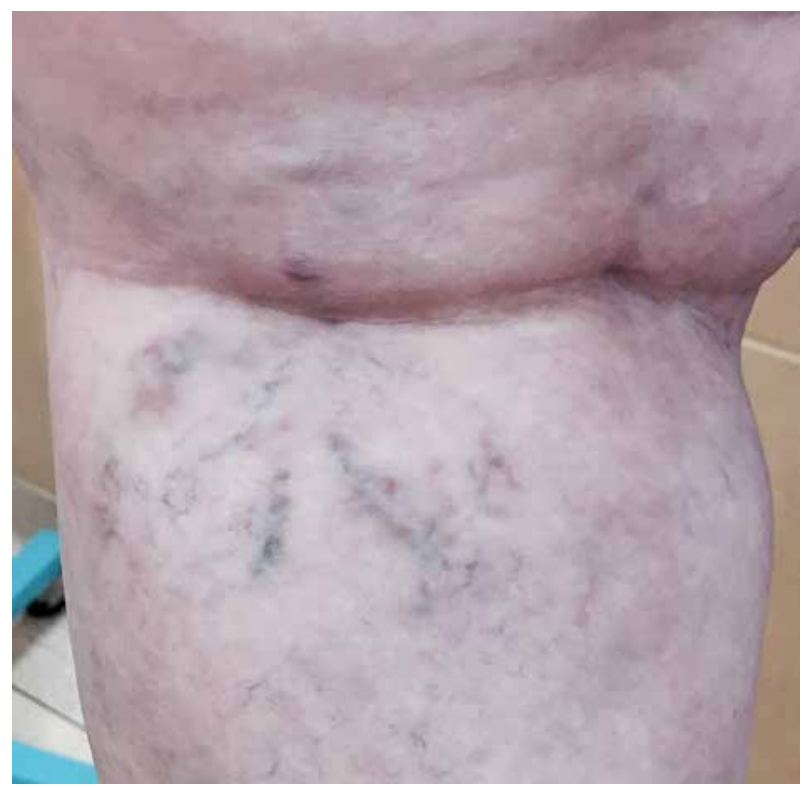

Fig. 12. Incompetent popliteal perforating vein three weeks after sclerotherapy

7. Myers K. A history of injection treatments - II sclerotherapy. Phlebology 2019; 34: 303-310.

8. Wollmann J-CGR. The history of sclerosing foams. Derm Surg 2004; 30: 694-703.

9. Orbach EJ. Sclerotherapy of varicose veins-utilization of an intravenous air block. Am J Surg 1944; 66: 362-366.

10. Fegan WG. Continuous compression technique of injecting varicose veins. Lancet 1963; 2: 109-112.

11. Tolins SH. Treatment of varicose veins. An update. Am J Surg 1983; 145: 248-252.

12. Geroulakos G. Foam sclerotherapy for the management of varicose veins: a critical reappraisal. Phlebolymphol 2006; 13: 202-206.

13. Cavezzi A, Tessari L. Foam sclerotherapy techniques: different gases and methods of preparation, catheter versus direct injection. Phlebology 2009; 24: 247-251.

14. Lai SW, Goldman MP. Does the relative silicone content of different syringes affect the stability of foam sclerotherapy? J Drugs Dermatol 2008; 7: 399-400.

15. Hawro P, Gabriel M, Madycki G, et al. Zalecenia dotyczące wykonywania ultrasonograficznego badania dopplerowskiego żył kończyn dolnych Polskiego Towarzystwa Chirurgii Naczyniowej i Polskiego Towarzystwa Flebologicznego. Acta Angiologica 2013; 19: 99-117.

16. Rabe E, Breu FX, Cavezzi A, et al. European guidelines for sclerotherapy in chronic venous disorders. Phlebology 2014; 29: 338-354.

17. Iłżecki M, Terlecki P, Przywara $S$, et al. The novel minimally invasive mechano-chemical technique of the saphenous vein ablation. Our center experience: results of 24 months follow-up. Acta Angiologica 2019; 25: 127-132.

18. Witte ME, Zeebregts CJ, de Borst GJ, et al. Mechanochemical endovenous ablation of saphenous veins using the ClariVein: a systematic review. Phlebology 2017; 32: 649-657.

19. ESVS, European Society for Vascular Surgery. Przewlekła choroba żylna. Wytyczne postępowania klinicznego Europejskiego Towarzystwa Chirurgii Naczyniowej. Eur J Vasc Endovas Surg 2015; 49: 678-737. 